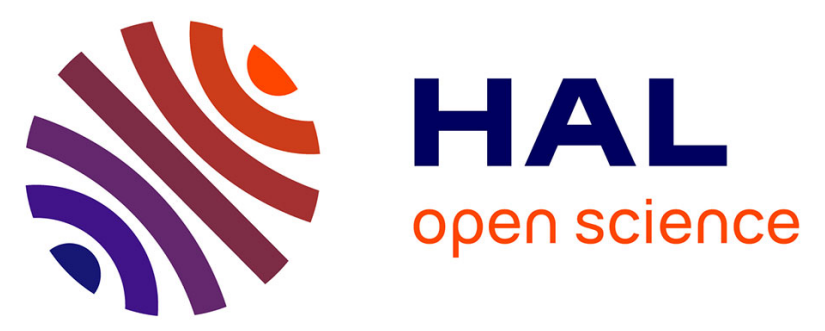

\title{
Effect of Ion Migration-Induced Electrode Degradation on the Operational Stability of Perovskite Solar Cells
}

Boris Rivkin, Paul Fassl, Qing Sun, Alexander Taylor, Zhuoying Chen, Yana Vaynzof

\section{- To cite this version:}

Boris Rivkin, Paul Fassl, Qing Sun, Alexander Taylor, Zhuoying Chen, et al.. Effect of Ion MigrationInduced Electrode Degradation on the Operational Stability of Perovskite Solar Cells. ACS Omega, 2018, 3 (8), pp.10042-10047. 10.1021/acsomega.8b01626 . hal-01896547

\section{HAL Id: hal-01896547 \\ https: / hal.sorbonne-universite.fr/hal-01896547}

Submitted on 16 Oct 2018

HAL is a multi-disciplinary open access archive for the deposit and dissemination of scientific research documents, whether they are published or not. The documents may come from teaching and research institutions in France or abroad, or from public or private research centers.
L'archive ouverte pluridisciplinaire HAL, est destinée au dépôt et à la diffusion de documents scientifiques de niveau recherche, publiés ou non, émanant des établissements d'enseignement et de recherche français ou étrangers, des laboratoires publics ou privés.

\section{(c)(1)}

Distributed under a Creative Commons Attribution| 4.0 International License 


\title{
Effect of Ion Migration-Induced Electrode Degradation on the Operational Stability of Perovskite Solar Cells
}

\author{
Boris Rivkin, ${ }^{\dagger, \neq}, \|$ Paul Fassl, ${ }^{\dagger, \ddagger}$ Qing Sun, ${ }^{\dagger, \ddagger}$ Alexander D. Taylor, ${ }^{\dagger, \ddagger}$ Zhuoying Chen, ${ }^{\S \odot}$ \\ and Yana Vaynzof $*,+\notin \bullet$ \\ ${ }^{\dagger}$ Kirchhoff Institute for Physics, Heidelberg University, Im Neuenheimer Feld 227, 69120 Heidelberg, Germany \\ ${ }^{\ddagger}$ Centre for Advanced Materials, Heidelberg University, Im Neuenheimer Feld 225, 69120 Heidelberg, Germany \\ ${ }^{\S}$ Laboratoire de Physique et d'Etude des Matériaux (LPEM), ESPCI Paris, PSL Research University, CNRS, Sorbonne Université, \\ 10 Rue Vauquelin, 75005 Paris, France
}

\section{Supporting Information}

\begin{abstract}
Perovskite-based solar cells are promising because of their rapidly improving efficiencies but suffer from instability issues. Recently, it has been claimed that one of the key contributors to the instability of perovskite solar cells is ion migration-induced electrode degradation, which can be avoided by incorporating inorganic hole-blocking layers (HBLs) in the device architecture. In this work, we investigate the operational environmental stability of methylammonium lead iodide perovskite solar cells that contain either an inorganic or organic HBL, with only the former effectively blocking ions from migrating to the metal electrode. This is confirmed by X-ray photoemission spectroscopy measured on the electrodes of degraded devices, where only electrodes of devices with an organic HBL show a significant iodine signal. Despite this, we show that when these devices are degraded under realistic operational conditions (i.e., constant illumination in a variety of atmospheric conditions), both types of devices exhibit nearly identical degradation behavior. These results demonstrate that contrary to prior suggestions, ion-induced electrode degradation is not the dominant factor in perovskite environmental instability under operational conditions.
\end{abstract}

\section{INTRODUCTION}

The favorable electronic and optical properties of hybrid lead halide perovskites have enabled the remarkable performance increase in solar cells based on such materials, which currently have reached a maximum efficiency of $22.7 \% .{ }^{1}$ Device stability, however, remains a major factor impeding their commercialization, where lifetimes of more than 25 years are required. ${ }^{2}$ Previous studies have investigated the degradation of device performance because of environmental factors such as oxygen, ${ }^{3-5}$ moisture, ${ }^{6-9}$ and heat, ${ }^{10,11}$ and explanatory models have been proposed for some scenarios. ${ }^{12,13}$ At the same time, device degradation under inert (nitrogen atmosphere) operating conditions is a widely observed but not conclusively explained phenomenon. ${ }^{14,15}$ In one popular model, it is claimed that device degradation originates predominantly from metal electrode corrosion: mobile halide ions, such as iodide, migrate through the active material and the adjacent electron extraction layer toward the metal cathodes, such as silver. ${ }^{16-20}$ This could then give rise to the formation of insulating silver iodine, ${ }^{21,22}$ which would inhibit the extraction of charges, increase series resistance, and enable the formation of an undesirable dipole interface layer. ${ }^{17,23}$ This hypothesis is often accompanied by the claim that a buffer layer of a dense electron-transporting material, such as $\mathrm{ZnO}, \mathrm{TiO}_{x}$, or $\mathrm{SnO}_{2}$, could serve as an "ion-blocking layer" and prohibit the migration of ions and thus improve the stability of perovskite solar cells. ${ }^{24-27}$ Although such studies have demonstrated increased device shelf life (dark storage) stability, few studies featuring full device degradation, under constant illumination and both inert and non-inert atmospheres, as well as employing rigorous compositional analysis to conclusively prove either of these two claims have been presented to date. ${ }^{27}$

In this work, we compare the environmental stability of methylammonium lead iodide $\left(\mathrm{MAPbI}_{3}\right)$ perovskite solar cells that contain inorganic $\mathrm{ZnO}$ nanoparticle-based hole-blocking layers (HBLs) against reference devices that employ the commonly used bathocuproine (BCP) as the HBL. While both types of devices show a similar initial photovoltaic (PV) performance, the inorganic $\mathrm{HBL}$ effectively blocks mobile iodide ions from reaching and reacting with the metal electrode. This is not the case for devices with an organic $\mathrm{HBL}$, in which a significant amount of iodine is detected by Xray photoemission spectroscopy (PES). Characterizing the environmental stability of the two types of devices under illumination allows us to probe the role of ion-induced electrode degradation on the stability of the devices in various

Received: July 12, 2018

Accepted: July 27, 2018

Published: August 28, 2018 
atmospheres. We find that both types of devices show very similar degradation dynamics, revealing that suppressing ioninduced electrode degradation does not improve the operational stability of these cells.

\section{RESULTS AND DISCUSSION}

To investigate the effect of ion-induced electrode degradation on the operational stability of perovskite solar cells, we study the degradation of complete cells using $\mathrm{MAPbI}_{3}$ in the inverted indium tin oxide (ITO)/poly( 3,4 -ethylene dioxythiophene):poly(styrene sulfonate) (PEDOT:PSS)/ $\mathrm{MAPbI}_{3} /[6,6]$-phenyl-C61-butyric acid methyl ester $(\mathrm{PCBM}) / \mathrm{HBL} / \mathrm{Ag}$ architecture, as displayed in Figure 1 . We

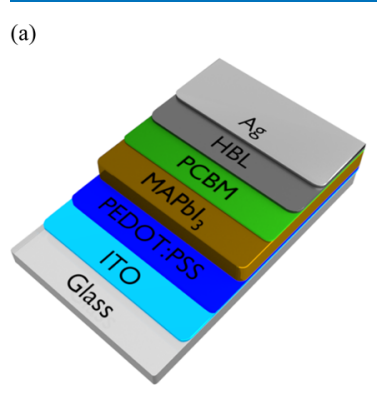

(c)
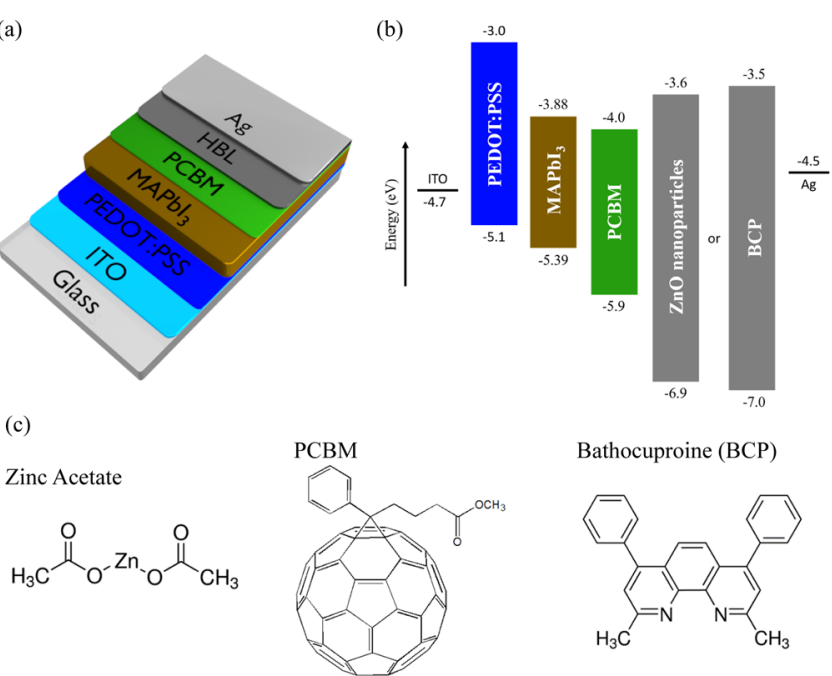

Figure 1. (a) Device architecture, (b) energy diagram, and (c) electron-transporting layer/HBL materials used.

fabricate two types of perovskite solar cells: one with the commonly used organic BCP and another with $\mathrm{ZnO}$ nanoparticles as $\mathrm{HBL}$, with all other layers fabricated in an identical fashion. In order to provide the best possible comparison of the degradation behavior between devices with the two HBLs, our first step was to optimize the thickness of the $\mathrm{ZnO}$ layer to achieve comparable initial PV performance of the two types of devices with similar charge extraction efficiency and recombination. $\mathrm{ZnO}$ nanoparticles were deposited via spin-coating at various spin speeds, and the resulting device performance was measured under AM 1.5G solar illumination and is displayed in Figure 2. As the spin speed decreases (and thus the $\mathrm{ZnO}$ layer becomes thicker), the device performance first increases up to approximately $8 \mathrm{~nm}$ of $\mathrm{ZnO}$ thickness and then decreases with further increases in $\mathrm{ZnO}$ thickness. At this thickness, both short-circuit current density $\left(J_{\mathrm{SC}}\right)$ and fill factor $(\mathrm{FF})$ are maximized, whereas the open-circuit voltage $\left(V_{\mathrm{OC}}\right)$ is largely independent of $\mathrm{HBL}$ thickness. At this optimal thickness, the $\mathrm{ZnO}$ devices possess comparable performance to the BCP reference devices. Typical $J-V$ curves for both device types are shown in Figure $\mathrm{S} 1$ (Supporting Information).

As mentioned before, previous work has suggested that one of the primary degradation mechanisms in perovskite-based devices is due to migration of ions toward, and subsequent reaction with, the metal electrodes. In the case of the devices in this study, this would be the migration of iodide to the silver electrode, which could then react with the silver to form the
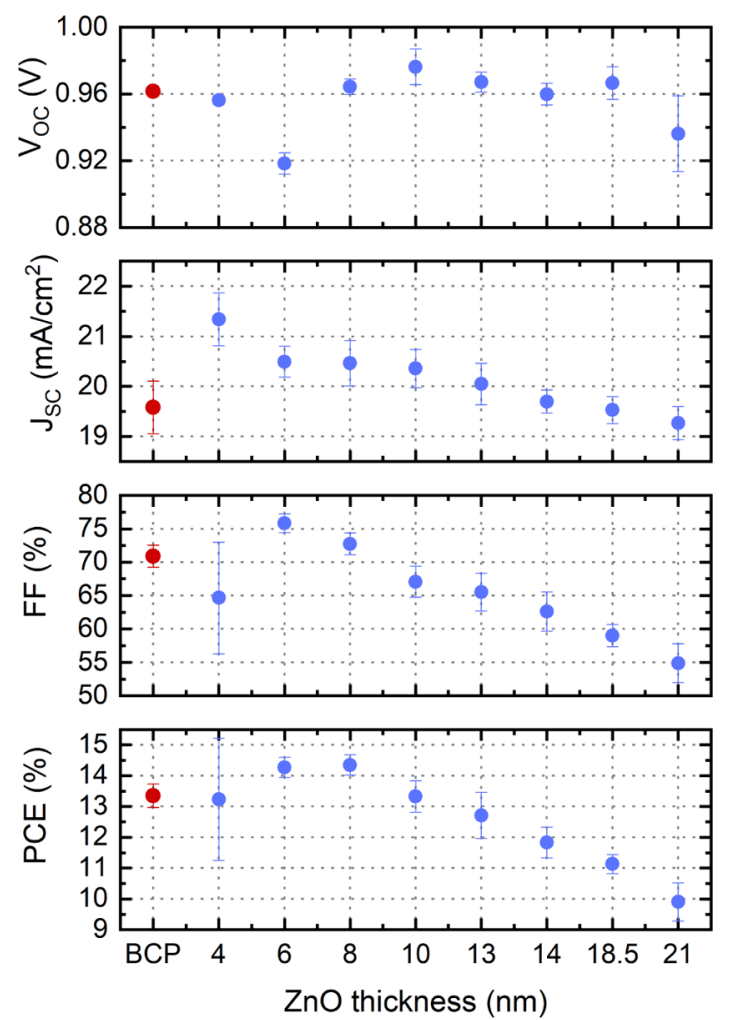

Figure 2. $\mathrm{PV}$ parameters as a function of $\mathrm{ZnO}$ nanoparticle layer thickness. One sample with BCP as the HBL was fabricated in the same batch for direct comparison. Error bars represent the standard deviation. An optimal value of $8 \mathrm{~nm}$ was found for $\mathrm{ZnO}$ nanoparticle layer's thickness.

insulator AgI. ${ }^{16,19,28}$ To examine whether the $\mathrm{ZnO} \mathrm{HBL}$ did effectively block iodide migration, both $\mathrm{ZnO}$ and $\mathrm{BCP}$ devices were degraded in an inert environment and under constant solar illumination for $14 \mathrm{~h}$, and afterward, the Ag electrodes were removed via a tape and characterized by X-ray photoelectron spectroscopy (XPS). This allowed us to look for the presence of iodine in the electrodes. We note that because XPS experiments are performed in ultrahigh vacuum, volatile iodine cannot be detected, so only the species of bound iodide, such as in metal iodides, would be detected. The I 3d signals for both the $\mathrm{ZnO}$ and $\mathrm{BCP}$ device electrodes are displayed in Figure 3a. While the BCP devices show a clear and strong I 3d signal, indicating that iodide has indeed reacted with the electrode, the $\mathrm{ZnO}$ devices, in contrast, show no presence of iodine. This confirms that on the timescale of the degradation experiment, a $\mathrm{ZnO} \mathrm{HBL}$ effectively blocks the migration of iodide ions into a metal electrode, most likely due to the layer's higher density when compared to BCP. Figure $3 \mathrm{~b}$ shows the excess iodine signal measured by XPS depth profiling, of degraded devices, from which the electrodes were peeled off. Similar to the results of Figure 3a, significant excess of iodine is detected in the PCBM extraction layer of the BCP device, whereas there is a far smaller iodine excess for the $\mathrm{ZnO}$ device. This result suggests that the inorganic HBL not only blocks iodide from reaching the metal electrode but also prevents $\mathrm{Ag}$ from penetrating into the PCBM layer during the thermal evaporation of the electrode, which in turn could also react with I ions. This mechanism has also been reported to be detrimental to the device performance. ${ }^{29}$ These results confirm that the incorporation of an inorganic HBL can suppress ion 

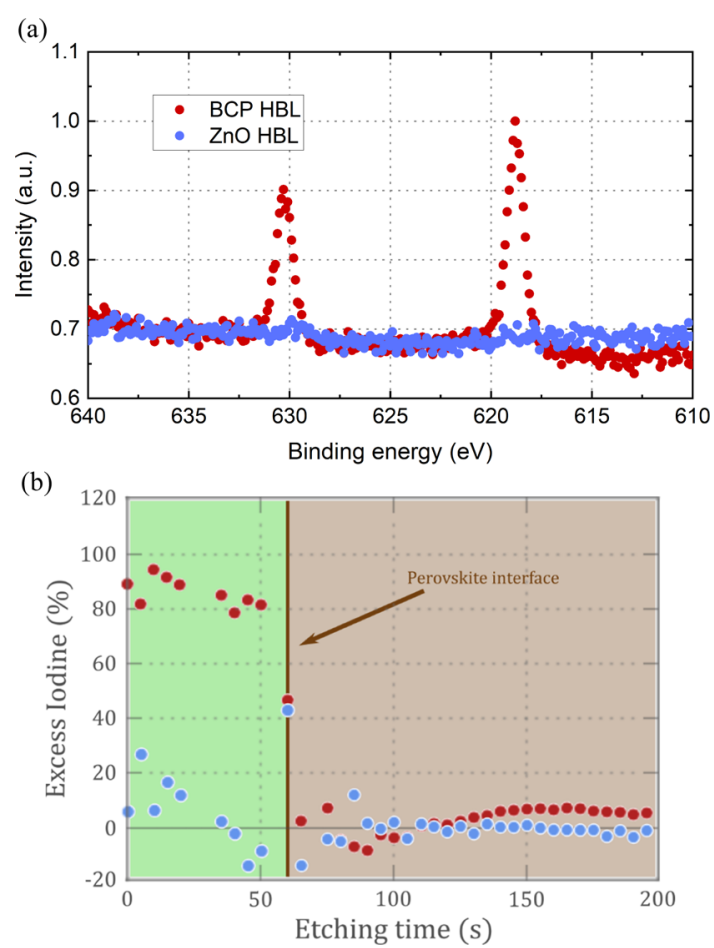

Figure 3. (a) XPS measurement of the surface of the Ag electrodes of fully degraded devices, showing the I $3 \mathrm{~d}$ (iodine) signal. (b) Excess iodine in the $\mathrm{Ag} / \mathrm{HBL} / \mathrm{PCBM}$ layer, obtained by XPS conducted after etching via argon beam. After approximately $60 \mathrm{~s}$ of etching, the interface with the perovskite film is reached.

migration-induced electrode degradation, whereas the organic HBL allowed for this degradation to take place.

Figure 4 displays the degradation behavior of the BCP devices under exposure to AM 1.5G solar illumination in the three different atmospheres: $\mathrm{N}_{2}$, dry air, and humidified $\mathrm{N}_{2}$ $[30 \%$ relative humidity $(\mathrm{RH})]$ with an additional period at $10-$
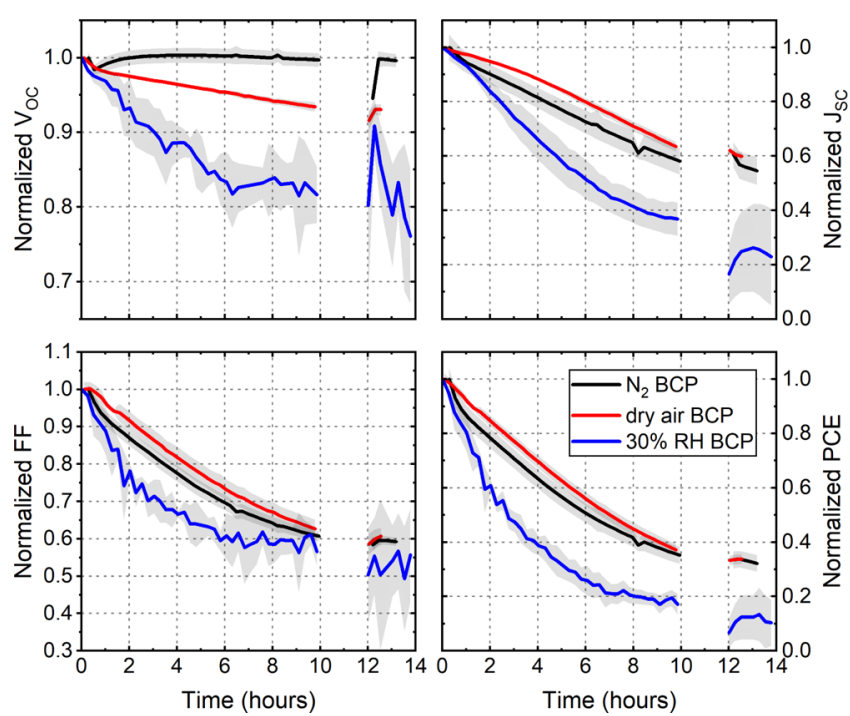

Figure 4. Evolution of PV parameters (open-circuit voltage, shortcircuit current, efficiency, and FF) for devices with BCP as the HBL, degraded in $\mathrm{N}_{2}$, dry air, and humidified $\mathrm{N}_{2}(30 \% \mathrm{RH})$ atmospheres over $14 \mathrm{~h}$. From 10 to $12 \mathrm{~h}$, the devices were left in the dark, in order to test the reversibility of the degradation. The shaded region represents the standard deviation for the measurement.
$12 \mathrm{~h}$ where the cells were left to rest in the dark to investigate possible performance recovery. ${ }^{14}$ We chose to compare three different degradation environments to eliminate the possibility that the difference in degradation dynamics would be associated with the different HBLs, rather than the ioninduced electrode degradation. Devices were held in the opencircuit condition while not being measured. During the $14 \mathrm{~h}$ measurement period, we observe a moderate to severe decrease across all PV parameters, with $V_{\mathrm{OC}}$ being the least affected and $J_{S C}$ the strongest. For the inert and dry air environments, $V_{\mathrm{OC}}$ retains above $90 \%$ of its initial value after $14 \mathrm{~h}$. The devices exposed to water dipped below $90 \%$ of $V_{\mathrm{OC}}$ after approximately $3 \mathrm{~h}$ of measurement. $J_{S C}$ and FF plummet in all cases, falling to $\sim 60$ and $20 \%$ of their initial values for $\mathrm{N}_{2}$ /dry air and $30 \% \mathrm{RH}$, respectively, and are the primary reasons for the steep loss in power conversion efficiency (PCE). Interestingly, there appears to be little difference between the degradation behavior in inert and dry air environments, with devices exposed to humidity degrading markedly faster than both. Additionally, exposure to humidity appears to affect the various pixels on each device differently, as evidenced by the jagged trend lines and significantly wider error margins.

The degradation behavior for the experimental devices employing $\mathrm{ZnO}$ as the $\mathrm{HBL}$, under identical degradation conditions, is displayed in Figure 5. Overall, the results are very
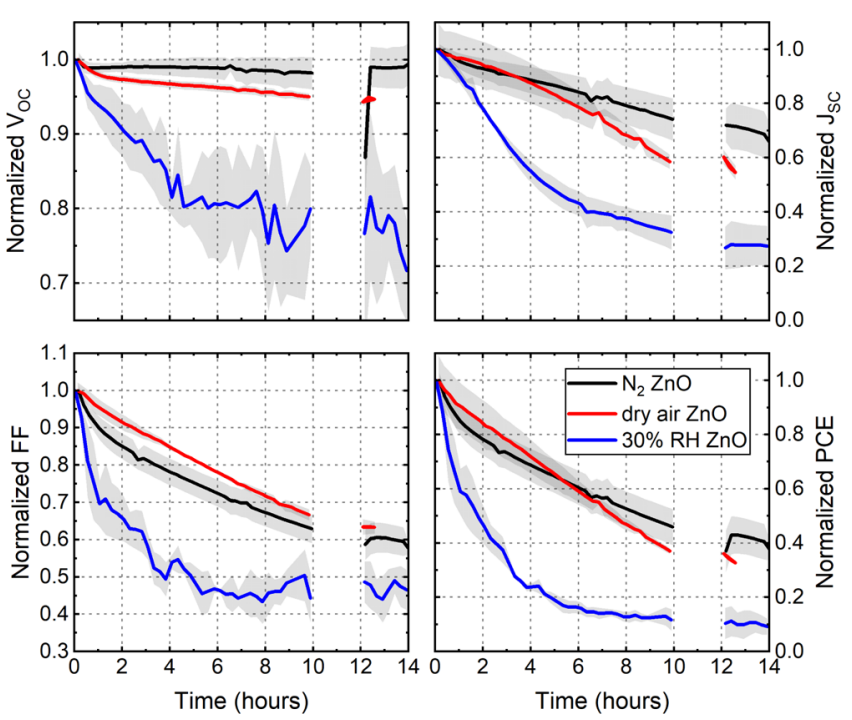

Figure 5. Evolution of PV parameters (open-circuit voltage, shortcircuit current, efficiency, and $\mathrm{FF}$ ) for devices with $\mathrm{ZnO}$ as the $\mathrm{HBL}$, degraded in $\mathrm{N}_{2}$, dry air, and humidified $\mathrm{N}_{2}(30 \% \mathrm{RH})$ atmospheres over $14 \mathrm{~h}$. From 10 to $12 \mathrm{~h}$, the devices were left in the dark, in order to test the reversibility of the degradation. The shaded region represents the standard deviation for the measurement.

similar to the BCP devices, with a relatively stable $V_{\mathrm{OC}}$ and strongly degraded $J_{\mathrm{SC}}$ and FF. Just like the reference devices, the effects under $\mathrm{N}_{2}$ and dry air atmospheres are identical, and exposure to water again degrades the devices both more quickly and less uniformly. The overall amount of degradation is slightly reduced for the $\mathrm{ZnO}$ devices, with the PCE falling to roughly $40 \%$ rather than $30 \%$ of their initial values. This is, however, only a slight improvement and could very easily be due to natural variation between the devices. 
Combining the degradation behavior with the XPS measurements of the electrodes yields two main conclusions. First, degradation for devices under constant illumination with the architecture ITO/PEDOT:PSS $/ \mathrm{CH}_{3} \mathrm{NH}_{3} \mathrm{PbI}_{3} / \mathrm{PCBM} /[\mathrm{BCP}$ or $\mathrm{ZnO}] / \mathrm{Ag}$ is not driven by an oxygen-related mechanism, as devices in both inert and dry air atmospheres displayed similar degradation characteristics. Aristidou et al. proposed that oxygen-related perovskite decomposition proceeds by the generation of photoexcited electrons within the perovskite crystal. ${ }^{3}$ Because PCBM is known to extract electrons from $\mathrm{MAPbI}_{3}$ on shorter timescales than chemical reactions can occur, $^{30}$ the presence of PCBM at the perovskite interface possibly prevents oxygen-related degradation by withdrawing photoexcited electrons rapidly after their formation. The presence of moisture accelerates the degradation, regardless of the HBL used. With several vulnerable components, the root cause of the rapid decay in moisture is difficult to isolate. For example, while water is known to have a significant impact on perovskite stability ${ }^{2,31-33}$ and also might facilitate the diffusion of volatile products inside the perovskite, ${ }^{26,34}$ PCBM has also been shown to undergo strong irreversible degradation in the presence of water. $^{35}$

The second overall conclusion is that in contrast to the prevailing view, $\mathrm{ZnO}$ HBLs do not significantly alter the degradation characteristics when compared to the more common HBL BCP. ${ }^{21}$ XPS measurements of degraded device electrodes did confirm that $\mathrm{ZnO}$ hinders the reaction of iodide ions with the electrode on the timescale of the experiment; however, there was no meaningful difference between the $\mathrm{ZnO}$ and BCP device performance deterioration. Han et al. ${ }^{36}$ found similar iodide infiltration into the silver electrode through the hole-transport layer Spiro-OMeTAD in their devices, accompanied with a dramatic loss in PCE. They suggested that replacement of the silver contact with a more chemically inert electrode, such as $\mathrm{Cu}$ or $\mathrm{C}$, could improve the device stability by preventing this modification. Our results suggest that this iodide infiltration, and subsequent modification of the electrode into a more insulating species, cannot be the dominant factor in the observed overall performance loss. Lee et al. previously showed that the removal and re-evaporation of the silver electrode in degraded devices did partially restore the device performance; ${ }^{19}$ however, a significant reduction in $J_{\mathrm{SC}}$ remained. This suggests that an additional irreversible degradation mechanism is present.

In a study related to our work, Back et al. demonstrated that a layer of titanium suboxide $\left(\mathrm{TiO}_{x}\right)$ placed between the PCBM and the silver electrode could effectively increase the device stability. ${ }^{27}$ Indeed, on similar timescales $(\sim 10 \mathrm{~h})$ to our experiments, devices with a $\mathrm{TiO}_{x}$ layer maintained $\sim 80 \%$ of their initial PCE, compared to $50 \%$ with our $\mathrm{ZnO} \mathrm{HBL}$. This seemingly contradictory result can be explained by two factors. First, their reference devices contained no HBL on top of the PCBM. It is widely known that directly evaporating metallic contacts onto organic films can damage and thereby harm the film stability. ${ }^{37}$ Therefore, the $\mathrm{TiO}_{x}$ layer will increase the device stability simply by protecting the PCBM during thermal evaporation. Second, Back et al. held their devices at the maximum power point, which has been shown to slow the degradation significantly when compared to devices held at $V_{\text {OC. }}{ }^{38}$ Once this difference is accounted for, the stability for devices containing $\mathrm{TiO}_{x}$ and $\mathrm{ZnO}$ nanoparticle blocking layers is extremely similar. In another study using a similar device structure, Akbulatov et al. demonstrated strongly enhanced stability when replacing PCBM with a perylene diimide derivative in encapsulated devices degraded in nitrogen under illumination. They attributed the strong degradation to the accumulation of volatile methylammonium iodide within the PCBM layer, subsequent reaction of iodide with the silver electrode, and the resulting formation of $\mathrm{PbI}_{2}$ inside the perovskite layer. ${ }^{20}$

Taken all these results together, a plausible explanation for the observed deterioration of the device performance is obtained by considering the effects of ion migration not on the electrode, but instead on the perovskite active layer. While the $\mathrm{ZnO}$ layer prevents iodide infiltration into the electrode, the diffusion of volatile components out of the perovskite layer into PCBM should still be possible (and would remain undetectable by XPS) and has been previously shown to initiate significant degradation, for example, by way of passivating the perovskite at the crystal grain boundaries. ${ }^{20,26,28,39}$ Passivation at the boundaries in turn isolates each individual grain, leading to difficulties in conduction and charge extraction. This conclusion is supported by the specific mechanism of degradation observed in our study, with the primary drivers of PCE deterioration being a loss of $J_{\mathrm{SC}}$ and FF, the two parameters associated with conductivity and charge extraction efficiency. Additionally, recently, Zhao et al. showed that the ion-induced degradation of charge extraction layers can also be a major cause for device instabilities. ${ }^{40}$ Our results indicate that even without the iodide migration-induced degradation of the electrode, the above-mentioned degradation pathways can still take place and strongly affect the device stability.

\section{CONCLUSIONS}

To summarize, we investigated the role of ion-induced electrode degradation in inverted perovskite PV devices under realistic operational conditions. We find that, contrary to what was previously suggested, suppressing degradation by blocking ion migration to the electrode does not necessarily improve the device stability significantly under operational conditions. Although it has been shown that this degradation mechanism plays a significant role in determining the longterm dark storage stability of devices, its significance is diminished once more prominent degradation processes are present under full illumination. We propose that it is not ionmigration induced electrode corrosion, but rather the diffusion of volatile products out of the perovskite active layer and into the PCBM layer, that causes strong and irreversible degradation under operational conditions. Further research is required to elucidate the exact role that ion migration plays in affecting the device performance and stability; however, this work shows that the scope of such research must encompass a thorough examination, under realistic operating conditions, of both the perovskite active layer and the other device components.

\section{EXPERIMENTAL METHODS}

Device Fabrication. If not stated otherwise, all materials were purchased from Sigma-Aldrich. To fabricate devices, prepatterned indium tin oxide (ITO)-coated glass substrates (Psiotech Ltd., $15 \Omega \mathrm{sq}^{-1}$ ) were first cleaned sequentially with acetone and 2-propanol, followed by $10 \mathrm{~min}$ oxygen plasma treatment. PEDOT:PSS (Clevios Al 4083, Heraeus) was spincoated onto the clean ITO substrates and then annealed at 150 
${ }^{\circ} \mathrm{C}$ for $10 \mathrm{~min}$ in air. For the perovskite layer fabricated by the lead acetate trihydrate recipe, $\mathrm{CH}_{3} \mathrm{NH}_{3} \mathrm{I}$ (GreatCell Solar) and $\mathrm{Pb}(\mathrm{Ac})_{2} \cdot 3\left(\mathrm{H}_{2} \mathrm{O}\right)$ (3:1, molar ratio) were dissolved in anhydrous $\mathrm{N}, \mathrm{N}$-dimethylformamide (DMF) with a concentration of $40 \mathrm{wt} \%$ with the addition of hypophosphorous acid solution $\left(6 \mu \mathrm{L} \mathrm{mL}{ }^{-1} \mathrm{DMF}\right)$. The perovskite solution was spincoated at $2000 \mathrm{rpm}$ for $60 \mathrm{~s}$ in a dry box $(\mathrm{RH}<0.5 \%)$. After drying for $5 \mathrm{~min}$, the samples were annealed at $100{ }^{\circ} \mathrm{C}$ for 5 min. Subsequently, the samples were transferred to a $\mathrm{N}_{2}$-filled glovebox. PCBM (Solenne BV) in chlorobenzene $(20 \mathrm{mg}$ $\mathrm{mL}^{-1}$ ) was dynamically spin-coated at $2000 \mathrm{rpm}$ for $45 \mathrm{~s}$ and annealed at $100{ }^{\circ} \mathrm{C}$ for $10 \mathrm{~min}$. BCP was fully dissolved in 2propanol $\left(0.5 \mathrm{mg} \mathrm{mL}^{-1}\right)$ and dynamically spin-coated at 4000 rpm for $30 \mathrm{~s}$. $\mathrm{ZnO}$ nanoparticles were synthesized following an adapted procedure of Pacholski, which is briefly described in Supporting Note $1 .^{41}$ The resulting nanoparticles were further characterized by UV-visible absorbance and transmission electron microscopy (TEM) (Figures S2 and S3, Supporting Information). TEM characterization was carried out by JEOL 2010 TEM $(200 \mathrm{kV})$ equipped with a Gatan camera. Single or multiple layers of $\mathrm{ZnO}$ were cast from colloidal solution to obtain layers of different thicknesses. To complete the device, $80 \mathrm{~nm}$ silver electrodes were deposited via thermal evaporation under high vacuum.

Device Characterization and Degradation. To properly assess the degradation of the perovskite solar cells, each device was identically prepared, stored in a nitrogen-filled glovebox, and transferred to a sealed environmental box without exposure to ambient air. A constant flow of either nitrogen, nitrogen and oxygen $(80: 20, \mathrm{v} / \mathrm{v})$, or humidified nitrogen (30\% RH) was connected to an environmental box. The oxygen percentage was controlled by adjusting the relative flow rate of $\mathrm{O}_{2}$ to $\mathrm{N}_{2}$ and monitored by a zirconia sensor (Cambridge Sensotet, Rapidox 2100) continuously before being connected to the environmental box. All of the devices were operated under simulated AM 1.5 sunlight at $100 \mathrm{~mW}$ $\mathrm{cm}^{-2}$ irradiance (Abet Sun 3000 Class AAA solar simulator) for $10 \mathrm{~h}$ (in open-circuit condition) and then "rested" in the dark for $2 \mathrm{~h}$ before another $2 \mathrm{~h}$ measurement period, bringing the total experiment time to $14 \mathrm{~h}$. This rest period was performed in response to Nie et al., who demonstrated that short rest periods could "heal" degraded devices. ${ }^{14}$ The $J-V$ measurements were performed with a Keithley 2450 source measure unit. The cells were scanned from forward bias to short circuit and back at a rate of $0.5 \mathrm{~V} \mathrm{~s}^{-1}$ after being held under illumination at $1.2 \mathrm{~V}$ for $2 \mathrm{~s}$. The light intensity was calibrated with a Si reference cell (NIST traceable, VLSI) and corrected by measuring the spectral mismatch between the solar spectrum, the spectral response of the perovskite solar cell, and the reference cell. The mismatch factor was calculated to be approximately $11 \%$.

X-ray PES and Depth Profiling. The perovskite devices investigated by PES measurements were fabricated and degraded as described above. The Ag electrodes were peeled off and transferred into an ultrahigh vacuum chamber of the PES system (Thermo Scientific ESCALAB 250Xi) for XPS measurements. XPS measurements were performed using an XR6 monochromated Al $\mathrm{K} \alpha$ source $(h \nu=1486.6 \mathrm{eV})$ and a pass energy of $20 \mathrm{eV}$. Depth profiles were performed on the remaining layers of the devices using a Magsic Ar etching source.

\section{ASSOCIATED CONTENT}

\section{Supporting Information}

The Supporting Information is available free of charge on the ACS Publications website at DOI: 10.1021/acsomega.8b01626.

Synthesis and characterization of $\mathrm{ZnO}$ nanoparticles, $J-$ $V$ curves of fresh PV devices, UV-vis measurements of $\mathrm{ZnO}$ nanoparticles, and TEM images of final $\mathrm{ZnO}$ nanoparticles (PDF)

\section{AUTHOR INFORMATION}

\section{Corresponding Author}

*E-mail: vaynzof@uni-heidelberg.de. ORCID $\odot$

Zhuoying Chen: 0000-0002-2535-5962

Yana Vaynzof: 0000-0002-0783-0707

\section{Present Address}

"Institute for Integrative Nanosciences (IIN), Leibniz Institute for Solid State and Materials Research, Helmholtzstr. 20, 01069 Dresden, Germany.

\section{Author Contributions}

The manuscript was written through contributions of all authors. All authors have given approval to the final version of the manuscript.

Notes

The authors declare no competing financial interest.

\section{ACKNOWLEDGMENTS}

The authors would like to kindly thank Prof. Uwe Bunz for providing access to the device fabrication facilities. P.F. thanks the HGSFP for scholarship. This work has received funding from the European Research Council (ERC) under the European Union's Horizon 2020 research and innovation programme (ERC Grant Agreement no. 714067, ENERGYMAPS). Y.V. and Z.C. thank the DFG (VA 991/2-1) and ANR (17-CE05-0028-01) for funding the joint project 'PROCES'.

\section{REFERENCES}

(1) Research Cell Efficiency Records: https://www.nrel.govfpv/ assets/images/efficiency-chart.png (accessed: July 2018).

(2) Leijtens, T.; Eperon, G. E.; Noel, N. K.; Habisreutinger, S. N.; Petrozza, A.; Snaith, H. J. Stability of Metal Halide Perovskite Solar Cells. Adv. Energy Mater. 2015, 5, 1500963.

(3) Aristidou, N.; Sanchez-Molina, I.; Chotchuangchutchaval, T.; Brown, M.; Martinez, L.; Rath, T.; Haque, S. A. The Role of Oxygen in the Degradation of Methylammonium Lead Trihalide Perovskite Photoactive Layers. Angew. Chem., Int. Ed. 2015, 54, 8208-8212.

(4) Sun, Q.; Fassl, P.; Becker-Koch, D.; Bausch, A.; Rivkin, B.; Bai, S.; Hopkinson, P. E.; Snaith, H. J.; Vaynzof, Y. Role of Microstructure in Oxygen Induced Photodegradation of Methylammonium Lead Triiodide Perovskite Films. Adv. Energy Mater. 2017, 7, 1700977.

(5) Bryant, D.; Aristidou, N.; Pont, S.; Sanchez-Molina, I.; Chotchunangatchaval, T.; Wheeler, S.; Durrant, J. R.; Haque, S. A. Light and Oxygen Induced Degradation Limits the Operational Stability of Methylammonium Lead Triiodide Perovskite Solar Cells. Energy Environ. Sci. 2016, 9, 1655-1660.

(6) Spina, M.; Karimi, A.; Andreoni, W.; Pignedoli, C. A.; Náfrádi, B.; Forró, L.; Horváth, E. Mechanical Signatures of Degradation of the Photovoltaic Perovskite CH3NH3PbI3upon Water Vapor Exposure. Appl. Phys. Lett. 2017, 110, 121903.

(7) Wang, Q.; Chen, B.; Liu, Y.; Deng, Y.; Bai, Y.; Dong, Q.; Huang, J. Scaling Behavior of Moisture-Induced Grain Degradation in 
Polycrystalline Hybrid Perovskite Thin Films. Energy Environ. Sci. 2017, 10, 516-522.

(8) Yang, J.; Siempelkamp, B. D.; Liu, D.; Kelly, T. L. Investigation of $\mathrm{CH} 3 \mathrm{NH} 3 \mathrm{PbI} 3$ Degradation Rates and Mechanisms in Controlled Humidity Environments Using in Situ Techniques. ACS Nano 2015, 9, 1955-1963.

(9) Dong, X.; Fang, X.; Lv, M.; Lin, B.; Zhang, S.; Ding, J.; Yuan, N. Improvement of the humidity stability of organic-inorganic perovskite solar cells using ultrathin $\mathrm{Al} 2 \mathrm{O} 3$ layers prepared by atomic layer deposition. J. Mater. Chem. A 2015, 3, 5360-5367.

(10) Conings, B.; Drijkoningen, J.; Gauquelin, N.; Babayigit, A.; D'Haen, J.; D'Olieslaeger, L.; Ethirajan, A.; Verbeeck, J.; Manca, J.; Mosconi, E.; et al. Intrinsic Thermal Instability of Methylammonium Lead Trihalide Perovskite. Adv. Energy Mater. 2015, 5, 1500477.

(11) Dualeh, A.; Gao, P.; Seok, S. I.; Nazeeruddin, M. K.; Grätzel, M. Thermal Behavior of Methylammonium Lead-Trihalide Perovskite Photovoltaic Light Harvesters. Chem. Mater. 2014, 26, 6160-6164.

(12) Li, B.; Li, Y.; Zheng, C.; Gao, D.; Huang, W. Advancements in the Stability of Perovskite Solar Cells: Degradation Mechanisms and Improvement Approaches. RSC Adv. 2016, 6, 38079-38091.

(13) Wang, D.; Wright, M.; Elumalai, N. K.; Uddin, A. Stability of Perovskite Solar Cells. Sol. Energy Mater. Sol. Cells 2016, 147, 255275.

(14) Nie, W.; Blancon, J.-C.; Neukirch, A. J.; Appavoo, K.; Tsai, H.; Chhowalla, M.; Alam, M. A.; Sfeir, M. Y.; Katan, C.; Even, J.; et al. Light-Activated Photocurrent Degradation and Self-Healing in Perovskite Solar Cells. Nat. Commun. 2016, 7, 11574.

(15) Xiao, Z.; Yuan, Y.; Shao, Y.; Wang, Q.; Dong, Q.; Bi, C.; Sharma, P.; Gruverman, A.; Huang, J. Giant Switchable Photovoltaic Effect in Organometal Trihalide Perovskite Devices. Nat. Mater. 2015, 14, 193-198.

(16) Li, C.; Guerrero, A.; Zhong, Y.; Gräser, A.; Luna, C. A. M.; Köhler, J.; Bisquert, J.; Hildner, R.; Huettner, S. Real-Time Observation of Iodide Ion Migration in Methylammonium Lead Halide Perovskites. Small 2017, 13, 1701711.

(17) Guerrero, A.; You, J.; Aranda, C.; Kang, Y. S.; Garcia-Belmonte, G.; Zhou, H.; Bisquert, J.; Yang, Y. Interfacial Degradation of Planar Lead Halide Perovskite Solar Cells. ACS Nano 2016, 10, 218-224.

(18) Tress, W.; Marinova, N.; Moehl, T.; Zakeeruddin, S. M.; Nazeeruddin, M. K.; Grätzel, M. Understanding the rate-dependent J$\mathrm{V}$ hysteresis, slow time component, and aging in $\mathrm{CH} 3 \mathrm{NH} 3 \mathrm{PbI} 3$ perovskite solar cells: the role of a compensated electric field. Energy Environ. Sci. 2015, 8, 995-1004.

(19) Lee, H.; Lee, C. Analysis of Ion-Diffusion-Induced Interface Degradation in Inverted Perovskite Solar Cells via Restoration of the Ag Electrode. Adv. Energy Mater. 2017, 8, 1702197.

(20) Akbulatov, A. F.; Frolova, L. A.; Griffin, M. P.; Gearba, I. R.; Dolocan, A.; Bout, D. A. V.; Tsarev, S.; Katz, E. A.; Shestakov, A. F.; Stevenson, K. J.; et al. Effect of Electron-Transport Material on LightInduced Degradation of Inverted Planar Junction Perovskite Solar Cells. Adv. Energy Mater. 2017, 7, 1700476.

(21) Kato, Y.; Ono, L. K.; Lee, M. V.; Wang, S.; Raga, S. R.; Qi, Y. Silver Iodide Formation in Methyl Ammonium Lead Iodide Perovskite Solar Cells with Silver Top Electrodes. Adv. Mater. Interfaces 2015, 2, 1500195.

(22) Yuan, Y.; Wang, Q.; Shao, Y.; Lu, H.; Li, T.; Gruverman, A.; Huang, J. Electric-Field-Driven Reversible Conversion between Methylammonium Lead Triiodide Perovskites and Lead Iodide at Elevated Temperatures. Adv. Energy Mater. 2016, 6, 1501803.

(23) Yang, D.; Ming, W.; Shi, H.; Zhang, L.; Du, M.-H. Fast Diffusion of Native Defects and Impurities in Perovskite Solar Cell Material CH3NH3PbI3. Chem. Mater. 2016, 28, 4349-4357.

(24) You, J.; Meng, L.; Song, T.-B.; Guo, T.-F.; Chang, W.-H.; Hong, Z.; Chen, H.; Zhou, H.; Chen, Q.; Liu, Y.; et al. Improved Air Stability of Perovskite Solar Cells via Solution-Processed Metal Oxide Transport Layers. Nat. Nanotechnol. 2016, 11, 75-81.

(25) Bai, S.; Wu, Z.; Wu, X.; Jin, Y.; Zhao, N.; Chen, Z.; Mei, Q.; Wang, X.; Ye, Z.; Song, T.; et al. High-Performance Planar Heterojunction Perovskite Solar Cells: Preserving Long Charge
Carrier Diffusion Lengths and Interfacial Engineering. Nano Res. 2014, 7, 1749-1758.

(26) Brinkmann, K. O.; Zhao, J.; Pourdavoud, N.; Becker, T.; Hu, T.; Olthof, S.; Meerholz, K.; Hoffmann, L.; Gahlmann, T.; Heiderhoff, R.; et al. Suppressed Decomposition of Organometal Halide Perovskites by Impermeable Electron-Extraction Layers in Inverted Solar Cells. Nat. Commun. 2017, 8, 13938.

(27) Back, H.; Kim, G.; Kim, J.; Kong, J.; Kim, T. K.; Kang, H.; Kim, H.; Lee, J.; Lee, S.; Lee, K. Achieving long-term stable perovskite solar cells via ion neutralization. Energy Environ. Sci. 2016, 9, 1258-1263.

(28) Li, J.; Dong, Q.; Li, N.; Wang, L. Direct Evidence of Ion Diffusion for the Silver-Electrode-Induced Thermal Degradation of Inverted Perovskite Solar Cells. Adv. Energy Mater. 2017, 7, 1602922.

(29) Zhang, T.; Meng, X.; Bai, Y.; Xiao, S.; Hu, C.; Yang, Y.; Chen, H.; Yang, S. Profiling the Organic Cation-Dependent Degradation of Organolead Halide Perovskite Solar Cells. J. Mater. Chem. A 2017, 5, $1103-1111$.

(30) Chueh, C.-C.; Li, C.-Z.; Jen, A. K.-Y. Recent Progress and Perspective in Solution-Processed Interfacial Materials for Efficient and Stable Polymer and Organometal Perovskite Solar Cells. Energy Environ. Sci. 2015, 8, 1160-1189.

(31) Frost, J. M.; Butler, K. T.; Brivio, F.; Hendon, C. H.; van Schilfgaarde, M.; Walsh, A. Atomistic Origins of High-Performance in Hybrid Halide Perovskite Solar Cells. Nano Lett. 2014, 14, 25842590.

(32) Kang, S. M.; Ahn, N.; Lee, J.-W.; Choi, M.; Park, N.-G. Waterrepellent perovskite solar cell. J. Mater. Chem. A 2014, 2, 2001720021.

(33) Huang, J.; Tan, S.; Lund, P. D.; Zhou, H. Impact of H2O on Organic-Inorganic Hybrid Perovskite Solar Cells. Energy Environ. Sci. 2017, 10, 2284-2311.

(34) Ma, C.; Shen, D.; Qing, J.; Thachoth Chandran, H.; Lo, M.-F.; Lee, C.-S. Effects of Small Polar Molecules (MA+ and H2O) on Degradation Processes of Perovskite Solar Cells. ACS Appl. Mater. Interfaces 2017, 9, 14960-14966.

(35) Bao, Q.; Liu, X.; Braun, S.; Fahlman, M. Oxygen- and WaterBased Degradation in [6,6]-Phenyl-C61-Butyric Acid Methyl Ester (PCBM) Films. Adv. Energy Mater. 2014, 4, 1301272.

(36) Han, Y.; Meyer, S.; Dkhissi, Y.; Weber, K.; Pringle, J. M.; Bach, U.; Spiccia, L.; Cheng, Y.-B. Degradation observations of encapsulated planar $\mathrm{CH} 3 \mathrm{NH} 3 \mathrm{PbI} 3$ perovskite solar cells at high temperatures and humidity. J. Mater. Chem. A 2015, 3, 8139-8147.

(37) Jørgensen, M.; Norrman, K.; Krebs, F. C. Stability/Degradation of Polymer Solar Cells. Sol. Energy Mater. Sol. Cells 2008, 92, 686714.

(38) Domanski, K.; Alharbi, E. A.; Hagfeldt, A.; Grätzel, M.; Tress, W. Systematic Investigation of the Impact of Operation Conditions on the Degradation Behaviour of Perovskite Solar Cells. Nat. Energy 2018, 3, 61-67.

(39) Chen, Q.; Zhou, H.; Song, T.-B.; Luo, S.; Hong, Z.; Duan, H.S.; Dou, L.; Liu, Y.; Yang, Y. Controllable Self-Induced Passivation of Hybrid Lead Iodide Perovskites toward High Performance Solar Cells. Nano Lett. 2014, 14, 4158-4163.

(40) Zhao, Y.; Zhou, W.; Tan, H.; Fu, R.; Li, Q.; Lin, F.; Yu, D.; Walters, G.; Sargent, E. H.; Zhao, Q. Mobile-Ion-Induced Degradation of Organic Hole-Selective Layers in Perovskite Solar Cells. J. Phys. Chem. C 2017, 121, 14517-14523.

(41) Pacholski, C.; Kornowski, A.; Weller, H. Self-Assembly of ZnO: From Nanodots to Nanorods. Angew. Chem., Int. Ed. 2002, 41, 11881191. 